\title{
Composição química de tubérculos de batata para processamento, cultivados sob diferentes doses e fontes de potássio
}

\author{
Chemical composition of potato tubers for processing, grown in different levels and sources of potassium
}

Diomar Augusto de QUADROS ${ }^{1,2 *}$, Maurício Cesar IUNG ${ }^{3}$, Sila Mary Rodrigues FERREIRA ${ }^{4}$, Renato João Sossela de FREITAS ${ }^{2}$

\begin{abstract}
Resumo
A batata é considerada um dos poucos alimentos capazes de nutrir a crescente população mundial por ser fonte de energia e conter elevado teor de proteínas, vitaminas e minerais. Porém os teores desses compostos sofrem influência de diversos fatores como: cultivar utilizada, condições edafoclimáticas, safra, colheita e armazenamento. Assim, o presente trabalho teve como objetivo determinar a composição química de batatas (cvs. Atlantic, Asterix, Innovator e Shepody), cultivadas em quatro doses (0,120,360 e $1080 \mathrm{~kg} \mathrm{~K}_{2} \mathrm{O}^{-h a^{-1}}$ ) e duas fontes de potássio $\left(\mathrm{KCl} \mathrm{e}_{2} \mathrm{SO}_{4}\right.$ ). As amostras foram provenientes do município de Fazenda Rio Grande/PR, cultivadas na safra das águas. Foram realizadas as seguintes determinações: vitamina $\mathrm{C}$, umidade, proteínas, lipídios, cinzas, carboidratos, energia, amido e potássio. A cv. Atlantic apresentou os maiores teores médios de cinzas $(0,93 \%)$ e potássio $\left(528,80 \mathrm{mg} .100 \mathrm{~g}^{-1}\right)$; a cv. Asterix, a maior umidade (81,47\%); a cv. Innovator, os maiores teores de proteínas (2,25\%), lipídios (0,06\%), carboidratos (17,72\%), energia (80,40 kcal.100 g-1) e amido (16,45\%); e a cv. Shepody obteve a maior quantidade de vitamina C $\left(31,01 \mathrm{mg} \cdot 100 \mathrm{~g}^{-1}\right)$. Pode-se concluir que a composição química das batatas é dependente da cultivar e da adubação potássica (dose e fonte) empregada.
\end{abstract}

Palavras-chave: Solanum tuberosum; composição; adubação potássica.

\begin{abstract}
Potato is considered one of the few foods able to nourish the growing world population for being a source of energy and containing high levels of proteins, vitamins, and minerals. However, these compounds suffer influence of several factors such as the use of cultivars, soil and climate characteristics, crop, harvest, and storage. Hence, the present paper aims to determine the potato chemical composition (cvs. Atlantic, Asterix, Innovator and Shepody), grown under four different levels $\left(0,120,360\right.$ and $\left.1080 \mathrm{~kg} \mathrm{~K}_{2} \mathrm{O}^{-h^{-1}}\right)$ and two different sources of potassium $\left(\mathrm{KCl}\right.$ e $\mathrm{K}_{2} \mathrm{SO}_{4}$ ). Samples of crop water production were collected from a farm in the city of Fazenda Rio Grande/PR, Brazil. The following criteria were determined: vitamin C, moisture, proteins, fat, ashes, carbohydrates, energy, starch content, and potassium. The Atlantic cultivar presented the highest average ashes content $(0.93 \%)$ and potassium $\left(528.80 \mathrm{kcal} 100 \mathrm{~g} \mathrm{~g}^{-1}\right)$; Asterix presented the highest moisture content

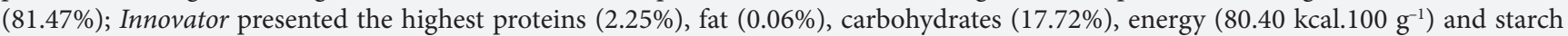
content (16.45\%); and the Shepody presented the highest vitamin C amount (31.01 mg.100 g-1). It can be concluded that the potato chemical composition depends on the potassium fertilization (level and source).

Keywords: Solanum tuberosum; composition; potassium fertilization.
\end{abstract}

\section{Introdução}

A batata (Solanum tuberosum L.) é a olerícola de maior importância comercial para o Brasil (PAULETTI; MENARIN, 2004; PINELI et al., 2005; ZORZELLA et al., 2003) pelo seu alto potencial de rendimento e pelas suas propriedades nutricionais (CONCEIÇÃO; FORTES; SILVA, 1999), sendo essencial para países populosos por conter elevado teor de vitamina $C$, proteínas, carboidratos e potássio (NAKANO; DELEO; BOTEON, 2006) e, em nível, mundial é o quarto alimento mais consumido (PINELI et al., 2006).

A indústria proporciona novas oportunidades de mercado, requerendo o uso de cultivares adequadas para cada propósito, tendo a necessidade de um volume de vendas mínimo e entrega durante $\mathrm{o}$ ano todo com produtos capazes de satisfazer os padrões de marketing rígidos da indústria de processamento (SALAZAR; BUSCH, 2001). No entanto, o desenvolvimento da indústria de batata processada é dificultado pela falta de matéria-prima de qualidade e fornecimento regular por parte dos produtores (BREGAGNOLI, 2006).

A fim de garantir a produtividade, a cultura recebe altas doses de fertilizantes, os quais muitas vezes são utilizados de maneira indiscriminada (MALLMANN; LUCCHESI, 2002). O potássio geralmente é fornecido em maior quantidade, por ser o nutriente mais exigido pela planta, cuja ausência compromete o metabolismo (PAULETTI; MENARIN, 2004; REIS JÚNIOR; MONNERAT, 2001).

Recebido para publicação em 8/10/2007

Aceito para publicação em 7/4/2008 (002865)

${ }^{1}$ Setor Litoral, Universidade Federal do Paraná - UFPR, Rua Jaguaraíva, 512, Caiobá, CEP 83260-000, Matinhos - PR, Brasil, E-mail: diomar@ufpr.br

2 Programa de Pós-Graduação em Tecnologia de Alimentos, Universidade Federal do Paraná - UFPR

3 Programa de Pós-Graduação em Ciência do Solo, Universidade Federal do Paraná - UFPR

${ }^{4}$ Departamento de Nutrição, Universidade Federal do Paraná - UFPR

${ }^{*}$ A quem a correspondência deve ser enviada 
Mesmo não participando diretamente de substâncias químicas nas plantas (MALLMANN, 2001), o potássio está envolvido em vários processos fisiológicos, como cofator enzimático para mais de 40 enzimas; é o regulador do potencial osmótico nas células e ativador de enzimas da respiração e do processo de fotossíntese (TAIZ; ZEIGER, 2004). O potássio também regula a abertura dos estômatos e a translocação de nutrientes, promove a absorção de água, aumenta a absorção de nitrogênio e a síntese de proteínas (IMAS; BANSAL, 1999), atua na formação dos carboidratos e na transformação destes em amido, favorecendo o transporte na folha até serem estocados nos tubérculos (DARWISH, 2007).

Em adubações excessivas de potássio, ocorre uma maior absorção e acúmulo na planta. Isto reduz o potencial osmótico e aumenta a absorção de água, o que causa diluição do amido devido ao aumento da umidade dos tubérculos (PAULETTI; MENARIN, 2004).

Maccari Júnior (1997) e Trindade (1994) citam diversos fatores que afetam a composição química da batata, como: a cultivar, estádios de maturação, condições ambientais, solo, clima, adubação e doenças.

No entanto, a análise da composição química de batata associada à adubação é pouco relatada na literatura, na qual geralmente as informações encontram-se de forma isolada. Em razão disso, este trabalho teve por objetivo determinar a composição química de batatas (cvs. Atlantic, Asterix, Innovator e Shepody) cultivadas em quatro doses $\left(0,120,360\right.$ e $\left.1080 \mathrm{~kg} \mathrm{~K}_{2} \mathrm{O} \mathrm{ha}{ }^{-1}\right)$ e duas fontes de potássio $\left(\mathrm{KCl}\right.$ e $\left.\mathrm{K}_{2} \mathrm{SO}_{4}\right)$.

\section{Material e métodos}

\subsection{Matéria-prima}

A matéria-prima foi composta por tubérculos de batata (Solanum tuberosum L.), cvs. Atlantic, Asterix, Innovator e Shepody, cultivados na safra das águas com quatro doses $(0,120,360 \mathrm{e}$ $1080 \mathrm{~kg} \mathrm{~K}_{2} \mathrm{O} \mathrm{ha}{ }^{-1}$ ) e duas fontes de adubação potássica (cloreto e sulfato), oriundos do município de Fazenda Rio Grande/PR. $\mathrm{Na}$ cultura foram feitos tratamentos sanitários conforme os praticados pelos agricultores da região.

A área experimental localiza-se em altitude de $910 \mathrm{~m} \mathrm{e}$ nas coordenadas $25^{\circ} 39^{\prime} 30^{\prime \prime} \mathrm{S}$ e $49^{\circ} 16^{\prime} 50^{\prime \prime} \mathrm{O}$. A classificação climática da região é Cfb. O solo, um Cambissolo Húmico Tb Distrófico típico.

\subsection{Amostragem}

A colheita foi realizada após o amadurecimento fisiológico das cultivares. Os tubérculos foram classificados e as amostras de tamanho comercial - classe 2 (maior diâmetro transversal igual ou maior que $45 \mathrm{~mm}$ ) foram conduzidas até os laboratórios do Departamento de Nutrição da Universidade Federal do Paraná para as análises químicas. Fizeram parte da amostragem 100 tubérculos e quando inferior, todo o lote constituiu a amostra (BRASIL, 1995).

\subsection{Composição química dos tubérculos}

A vitamina $C$ foi determinada por titulação com 2,6dicloroindofenol de acordo com o método 985.33 da AOAC (2000), sendo utilizados dez gramas de amostra.
A umidade foi determinada por gravimetria a $105^{\circ} \mathrm{C} \mathrm{em}$ estufa com circulação de ar até peso constante (BRASIL, 2005), sendo utilizados três tubérculos in natura, tomados de $1 \mathrm{~kg}$ de subamostra, os quais foram processados na forma de "palha" e pesados cinco gramas para a determinação.

As proteínas foram determinadas pelo nitrogênio total, empregando-se a técnica de Kjeldahl de acordo com o método 920.87 da AOAC (2000) e utilizando o fator de 6,25 para conversão em proteína bruta. As digestões das amostras foram realizadas em um digestor $V e l p^{\circledR}$ e a destilação em um equipamento Prodicil ${ }^{\circledR}$.

Os lipídios foram determinados por extração, utilizando-se éter de petróleo como solvente, durante seis horas em extrator Soxhlet, conforme método 945.39D da AOAC (2000).

As cinzas foram determinadas pela calcinação em mufla a $550{ }^{\circ} \mathrm{C}$, por quatro horas, adaptado do método 942.05 da AOAC (2000).

Os carboidratos foram calculados pela diferença entre $100 \mathrm{e}$ a soma das percentagens de umidade, proteínas, lipídios e cinzas, conforme TACO-UNICAMP (2006). Os valores de carboidratos incluíram a fibra alimentar total.

$\mathrm{O}$ valor energético ( $\mathrm{kcal}$ ) dos tubérculos foi calculado de acordo com TBCA-USP (2005), considerando-se os fatores de conversão de Atwater.

O amido foi estimado pela quantificação dos açúcares não redutores, calculados pela diferença entre carboidratos e açúcares redutores, expressos em glicose, sendo empregada a fórmula de Keer, segundo Maccari Júnior (1997).

A determinação de potássio foi realizada por espectrometria com chama, conforme método 956.01 da AOAC (2000). Inicialmente, a amostra seca foi calcinada a $550{ }^{\circ} \mathrm{C}$ em mufla e com as cinzas do produto foi realizado ataque ácido com $10 \mathrm{~mL}$ de $\mathrm{HCl} 3$ mol.L ${ }^{-1}$ e completado o volume para $100 \mathrm{~mL}$. Devido à grande quantidade de potássio na amostra foi feita uma diluição de 1:50 e na sequência a leitura direta em um espectrofotômetro de chama Digimed ${ }^{\oplus}$, modelo NK-2000. Para aferir o equipamento foi utilizado um padrão de potássio de 100 ppm. Antes do início das determinações, as vidrarias foram desmineralizadas com um solução de $\mathrm{HCl} 3 \%$.

Todas as determinações foram realizadas em triplicata.

\subsection{Preparo das amostras}

As determinações de vitamina $\mathrm{C}$ e umidade foram realizadas com tubérculos in natura, descascados. A fim de manter as características das amostras para as demais análises de composição química (proteínas, lipídios, cinzas, carboidratos, energia, amido e potássio), de três a cinco tubérculos/tratamento foram descascados, processados em fatias com o auxílio de um processador manual, secos a $55^{\circ} \mathrm{C}$ em forno vipinho Perfecta e moídos em um micromoinho Tecnal $^{\oplus}$ (LEONEL; CEREDA, 2002). Em seguida, foram acondicionados em envelopes plásticos, vedados com o auxílio de uma seladora elétrica Arno ${ }^{\circledast}$, colocados em uma caixa plástica com tampa e armazenados sob refrigeração até o momento das análises. 


\subsection{Análise estatística}

O delineamento utilizado foi em blocos ao acaso, com o esquema de parcelas subsubdivididas (split-split-plot). Foram 32 tratamentos testados $\left(4^{\star} 4^{\star} 2\right)$ com três repetições, os quais representaram a combinação de quatro cultivares (Atlantic, Asterix, Innovator e Shepody), aplicados às parcelas, quatro doses de potássio $\left(0,120,360\right.$ e $\left.1080 \mathrm{~kg} \mathrm{~K}_{2} \mathrm{O} \mathrm{ha}^{-1}\right)$ aplicadas às subparcelas e duas fontes de adubação potássica (cloreto e sulfato) aplicadas às subsubparcelas, fatores $\mathrm{A}, \mathrm{B}$ e $\mathrm{C}$, respectivamente.

Os dados foram submetidos à ANOVA e ao teste de Bartlett para averiguação da homogeneidade das variâncias para então serem submetidos ao teste de F. Quando os resultados mostraram existir diferenças estatisticamente significativas entre as médias dos tratamentos, foram comparados pelo Teste de Tukey ao nível de 5\% de significância ( $\mathrm{p} \leq 0,05)$ (KOEHLER, 1999). Para tanto, foi utilizado o programa MSTATC (versão 2.10 em sistema DOS) da Michigan State University - MSU (1989).

Quando a análise de variância mostrou significância para o efeito da dose em relação às variáveis dependentes, foram realizadas análises de regressão linear simples para cada cultivar plantada com determinada fonte a fim de verificar o efeito do aumento da adubação sobre a composição química.

\section{Resultados e discussão}

Na Tabela 1 encontram-se os resultados do teste $F$ da análise de variância e na Tabela 2 as médias da composição química dos tubérculos de batatas, cvs. Atlantic, Asterix, Innovator e Shepody, cultivados com diferentes doses e fontes de adubação potássica.

\subsection{Vitamina C}

Observando-se a Tabela 1, nota-se que a vitamina C é dependente da cultivar e da dose de adubação potássica utilizada. Esse comportamento está de acordo com Zorzella, Vendruscolo e Treptow (2003), que afirmam que a concentração da vitamina $\mathrm{C}$ depende principalmente da cultivar.

A vitamina $\mathrm{C}$ tendeu a diminuir com o aumento da dose de potássio utilizado. A análise de regressão linear mostrou que apenas a cv. Atlantic adubada com $\mathrm{K}_{2} \mathrm{SO}_{4}$ apresentou diferença estatística $(\mathrm{p} \leq 0,05)$ no declínio da vitamina $\mathrm{C}$ com o aumento da dose [vitamina $\mathrm{C}\left(\mathrm{mg} .100 \mathrm{~g} \mathrm{~g}^{-1}\right)=31,1217-2,08^{\star}$ dose $\mathrm{K}_{2} \mathrm{SO}_{4}$ ], estando em desacordo com a literatura, a qual menciona que a adubação potássica tem um efeito benéfico sobre os níveis de vitamina C (BREGAGNOLI, 2006; IMAS; BANSAL, 1999; LEE; KADER, 2000).

De acordo com Lee e Kader (2000) e Pineli et al. (2005), muitos fatores pré e pós-colheita influenciam o nível da vitamina C de olerícolas, como a variação genotípica, circunstâncias climáticas, manejo, maturidade na colheita, método da colheita e manipulação pós-colheita.

As médias de vitamina C (Tabela 2) estão de acordo com Pineli et al. (2005), pois para os autores as batatas apresentam teores de vitamina C entre 10 e $30 \mathrm{mg} .100 \mathrm{~g}^{-1}$ de matéria fresca. Pode ser observado ainda que a cv. Shepody mostrou ter mais vitamina C (31,01 mg.100 $\left.\mathrm{g}^{-1}\right)$ que as demais cultivares, sendo que a cv. Asterix apresentou o menor teor de vitamina $\mathrm{C}$ (21,63 mg.100 g-1).

A quantidade de vitamina $\mathrm{C}$ observada na cv. Atlantic (25,43 mg. $\left.100 \mathrm{~g}^{-1}\right)$ foi superior ao relatado por Love et al. (2003), que registraram $17,6 \mathrm{mg} .100 \mathrm{~g}^{-1}$ e aos $12,44 \mathrm{mg} .100 \mathrm{~g}^{-1}$ encontrados por Zorzella et al. (2003).

Rodriguez-Saona e Wrolstad (1997), analisando a composição de batatas, observaram valores de 12,0 a 23,4 mg. $100 \mathrm{~g}^{-1}$ de vitamina $\mathrm{C}$, sendo que esta variação é atribuída à diferença entre as cultivares, temperatura, manuseio dos tubérculos e estocagem (EREIFEJ et al., 1997).

\subsection{Umidade}

A análise de variância da umidade (Tabela 1) mostrou que a quantidade de água presente nos tubérculos depende dos fatores cultivar, dose, fonte e da interação dose $\times$ fonte. Popp (2005) destaca que a umidade varia em função de diversos fatores que interagem, entre os quais a cultivar, safra, condições de campo, adubação e disponibilidade de cloro.

A interação dose $\times$ fonte (Tabela 1 ) pode ser confirmada pela análise de regressão linear simples, que com o incremento da dose tende ao aumento da umidade nas batatas. $\mathrm{O}$ efeito da fonte cloreto mostrou diferença estatística com o aumento da dose para as cvs. Atlantic, Innovator e Shepody [cv. Atlantic $\mathrm{y}=77,95+0,69^{*} \mathrm{X} ; \mathrm{cv}$. Innovator $-\mathrm{y}=77,55+0,66^{*} \mathrm{X} ; \mathrm{cv}$. Shepody - $\mathrm{y}=78,72+0,69 \mathrm{X}$; sendo $\mathrm{y}=$ umidade $(\%)$ e $\mathrm{X}=$ dose de $\mathrm{KCl} \mathrm{e}$

Tabela 1. Teste $F$ da composição química dos tubérculos de batatas, cvs. Atlantic, Asterix, Innovator e Shepody, cultivados com diferentes doses e fontes de adubação potássica.

\begin{tabular}{|c|c|c|c|c|c|c|c|c|c|}
\hline \multirow[t]{2}{*}{ Fatores de Variação } & \multicolumn{9}{|c|}{ Teste $F$} \\
\hline & Vitamina $\mathrm{C}$ & Umidade & Proteínas & Lipídeos & Cinzas & Carboidratos & Energia & Amido & Potássio \\
\hline Cultivar $=$ Fator $\mathrm{A}$ & $10,70^{* *}$ & $9,05^{*}$ & $36,74^{* *}$ & $1,15^{\mathrm{ns}}$ & $66,51^{* *}$ & $6,39^{*}$ & $9,52^{* *}$ & $6,45^{*}$ & $61,72^{* *}$ \\
\hline Dose $\left(\mathrm{kg} \mathrm{K}_{2} \mathrm{O} \cdot \mathrm{ha}^{-1}\right)=$ Fator B & $6,41^{* *}$ & $3,73^{*}$ & $3,07^{*}$ & $0,72^{\text {ns }}$ & $60,79^{* *}$ & $3,66^{*}$ & $4,18^{*}$ & $3,64^{*}$ & $35,54^{* *}$ \\
\hline Fonte $=$ Fator $\mathrm{C}$ & $2,62^{\text {ns }}$ & $8,57^{* *}$ & $2,46^{\mathrm{ns}}$ & $1,21^{\mathrm{ns}}$ & $12,12^{* *}$ & $6,79^{*}$ & $8,92^{* *}$ & $6,57^{* *}$ & $9,08^{* *}$ \\
\hline Teste $F$ Interação $\mathrm{A} \times \mathrm{B}$ & $2,45^{*}$ & $0,77^{\text {ns }}$ & $2,54^{*}$ & $1,26^{\mathrm{ns}}$ & $35,74^{* *}$ & $0,78^{\text {ns }}$ & $0,78^{\text {ns }}$ & $0,79^{\text {ns }}$ & $16,65^{* *}$ \\
\hline Teste $F$ Interação $\mathrm{A} \times \mathrm{C}$ & $0,57^{\text {ns }}$ & $1,34^{\mathrm{ns}}$ & $0,18^{\text {ns }}$ & $0,35^{\text {ns }}$ & $7,78^{* *}$ & $1,42^{\text {ns }}$ & $1,44^{\mathrm{ns}}$ & $1,41^{\mathrm{ns}}$ & $2,04^{\mathrm{ns}}$ \\
\hline Teste $F$ Interação $\mathrm{B} \times \mathrm{C}$ & $0,36^{\text {ns }}$ & $4,20^{\text {ns }}$ & $0,38^{\text {ns }}$ & $1,57^{\mathrm{ns}}$ & $8,04^{* *}$ & $4,91^{* *}$ & $4,40^{* *}$ & $4,83^{* *}$ & $2,15^{\mathrm{ns}}$ \\
\hline Teste $F$ Interação $\mathrm{A} \times \mathrm{B} \times \mathrm{C}$ & $0,63^{\text {ns }}$ & $1,33^{\text {ns }}$ & $0,89^{\text {ns }}$ & $1,15^{\mathrm{ns}}$ & $10,34^{* *}$ & $1,47^{\mathrm{ns}}$ & $1,33^{\text {ns }}$ & $1,47^{\mathrm{ns}}$ & $4,63^{* *}$ \\
\hline
\end{tabular}

${ }^{(*)}$ significativo a $5 \%$ de probabilidade; ${ }^{(*)}$ significativo a $1 \%$ de probabilidade; ${ }^{(n)}$ não significativo. 
Quadros et al.

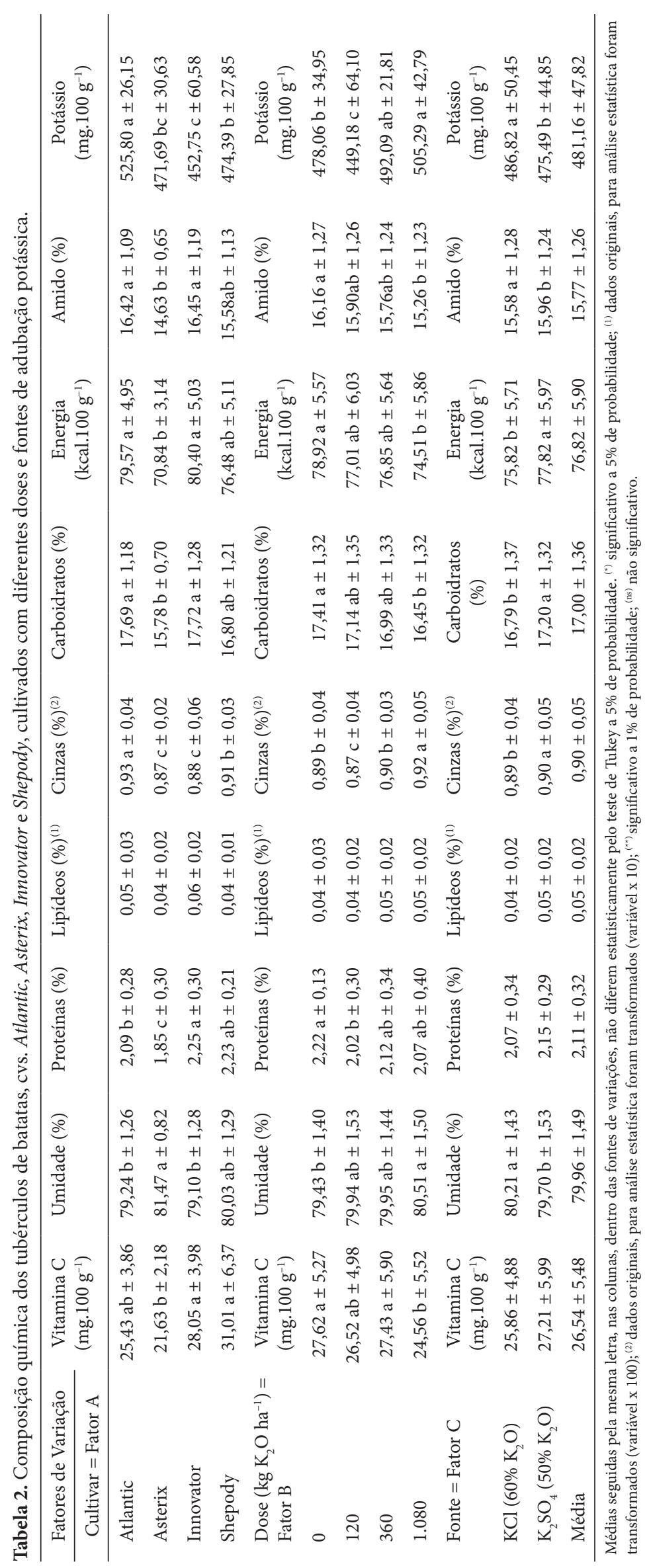


$\mathrm{Z}=$ dose $\mathrm{K}_{2} \mathrm{SO}_{4}$ ]. De acordo com Reis Júnior e Monnerat (2001), o aumento das doses de $\mathrm{K}_{2} \mathrm{SO}_{4}$ favorece $\mathrm{o}$ acúmulo de água nos tubérculos, devido à redução do potencial hídrico, o qual não foi observado neste trabalho. Quando a batata é destinada à indústria de fritas, baixo teor de umidade é desejado e a adubação potássica na forma de sulfato propicia os melhores resultados quando comparados com o cloreto (IMAS; BANSAL, 1999; WESTERMANN et al., 1994).

A umidade teve variação média de $79,10 \%$ (cv. Innovator) a $81,47 \%$ (cv. Asterix), conforme Tabela 2. De acordo com Favoretto (2005) e Maccari Júnior (1997), a umidade na batata varia de 63,2 a $86,9 \%$. A Tabela brasileira de composição química dos alimentos (TACO-UNICAMP, 2006) demonstra que as batatas brasileiras apresentam $82,9 \%$ de umidade.

No Paraná, Trindade (1994), estudando cultivares de batatas plantadas em Contenda/PR e sua indicação culinária, observou valores semelhantes de umidade, os quais variaram de 79,38 a $84,46 \%$. Jorge e Lunardi (2005) utilizaram em seus estudos de absorção de óleos em batatas fritas tubérculos com $83,8 \%$ de umidade. Bregagnoli (2006), avaliando o efeito de diferentes adubações em solos de baixa fertilidade, encontrou umidade que variou de $77,2 \%$ (cv. Atlantic) a $80,5 \%$ (cv. Asterix), valores semelhantes aos encontrados neste trabalho. Stertz, Rosa e Freitas (2005) observaram que a batata, cv. Monalisa, cultivada no sistema convencional apresenta em média $82,22 \%$ de umidade, valor superior às cultivares utilizadas nesta pesquisa.

Umidade elevada faz com que os tubérculos não sejam indicados para fritura, podendo ser utilizados apenas para o cozimento. De acordo com Popp (2005), ao retirar a umidade o que resta nos tubérculos é a matéria seca, um importante fator que determina a qualidade da batata e o seu uso, influenciando na quantidade de óleo absorvido durante a fritura e a textura do produto final (ZORZELLA et al., 2003).

\subsection{Proteínas}

A análise de variância (Tabela 1) demonstrou que as proteínas são dependentes da cultivar e da dose de potássio utilizada. Foi observada tendência à diminuição nas proteínas com o aumento na dose de potássio fornecida, porém esse efeito não foi significativo ( $\mathrm{p} \leq 0,05)$. Sharma e Arora (1988) também não encontraram alterações nas proteínas com o aumento de dose de potássio, sendo seus teores médios de $2,5 \%$; semelhantes ao observado neste trabalho.

Na Tabela 2 pode ser observado que a cv. Asterix apresentou o menor valor proteico médio e a cv. Innovator o maior, 1,85 e $2,25 \%$, respectivamente. De acordo com Belanger et al. (2002), a concentração de proteínas difere entre cultivares, porém foi verificado que as cvs. Innovator e Shepody não diferiram estatisticamente entre si, sendo superiores às cvs. Atlantic e Asterix. Os autores relatam que os teores mais altos de proteínas na cv. Shepody podem ser devidos ao alto potencial de absorção de nitrogênio, comparado a outras cultivares.

Os resultados obtidos foram semelhantes aos da TACOUNICAMP (2006) (1,8\% de proteínas) e de Bregagnoli (2006), que observou teores de proteínas superiores a $2 \%$ para as cvs. Atlantic e Asterix. Ainda, os resultados estão de acordo com
Trindade (1994), o qual relata teores de proteínas na batata entre 0,69 e 4,63\%, e Favoretto (2005), citando que os tubérculos contêm em média 2,1\%. Stertz, Rosa e Freitas (2005) encontraram $1,32 \%$ de proteínas em batatas do cultivo convencional na Região Metropolitana de Curitiba/PR, sendo inferiores aos obtidos neste trabalho. O que pode contribuir para uma menor quantidade de proteínas durante a formação do tubérculo é o aumento da massa média e acúmulo de amido, que diminui a concentração de proteínas (BELANGER et al., 2002).

\subsection{Lipídios}

Independente da variedade ou adubação potássica (Tabela 1), os tubérculos terão quantidades ínfimas de lipídios, o que pode ser observado na Tabela 2. Os resultados das análises de lipídios não apresentaram diferenças significativas entre os tratamentos $(\mathrm{p} \leq 0,05)$, por isso não foi aplicada regressão linear.

O teor de lipídios médio (Tabela 2) encontrado foi de $0,05 \%$, confirmando os traços deste nutriente em batata citado na literatura (TACO-UNICAMP, 2006), o qual pode variar de 0,02 a $0,20 \%$ nos tubérculos (MACCARI JÚNIOR, 1997). Os teores encontrados foram inferiores ao relatado por Jorge e Lunardi (2005), que observaram 0,1\% de lipídios na cv. Monalisa, a Silva, Cerqueira e Silva (2003), que dizem que batatas in natura contêm em torno de $0,26 \%$ e a Stertz, Rosa e Freitas (2005), que obtiveram $0,14 \%$.

Bregagnoli (2006) observou que os lipídios variaram de 0,07 a $0,08 \%$ para a cv. Atlantic e de 0,06 a $0,11 \%$ para a cv. Asterix, sendo superiores ao encontrado na presente pesquisa.

\subsection{Cinzas}

A análise de regressão linear demonstrou que em quase todos os tratamentos foi observada uma tendência ao aumento nas cinzas com a elevação na dose de potássio fornecida, porém apenas a cv. Innovator adubada com cloreto [cinzas $(\%)=0,08+0,002 *$ dose de $\mathrm{KCl}$ e sulfato [ $\operatorname{cinzas}(\%)=0,08+0,01^{*}$ dose $\mathrm{K}_{2} \mathrm{SO}_{4}$ ] apresentou aumento estatisticamente significativo $(\mathrm{p} \leq 0,05)$ (Tabela 1$)$. De acordo com Reis Júnior e Monnerat (2001), a composição mineral é influenciada pela adubação com $\mathrm{K}_{2} \mathrm{SO}_{4}$.

A cv. Atlantic foi a que apresentou o maior teor de cinzas $(0,93 \%)$, sendo estatisticamente superior $(\mathrm{p} \leq 0,01)$ às demais cultivares (Tabela 2).

As cinzas obtidas foram superiores ao registrado por Stertz, Rosa e Freitas (2005), que encontraram uma média de 0,67\% nos tubérculos. A TACO-UNICAMP (2006) apresentou 0,6\% de cinzas e Trindade (1994) registrou uma variação de 0,40 a $0,87 \%$ nas cultivares analisadas. Este autor relata ainda que os teores aceitáveis de cinzas para batatas são de 0,44 a 1,90\%.

\subsection{Carboidratos}

Os carboidratos foram dependentes do tipo e da quantidade de potássio fornecido à cultura. A cultivar utilizada, a dose e a fonte, isoladamente, também interferiram nos teores observados (Tabela 1). 
A análise de regressão linear demonstrou que os carboidratos tendem a diminuir com o aumento da dose, sendo que apenas a cvs. Innovator [carboidratos $(\%)=19,6033-0,772667^{\star}$ dose de KCl] e Shepody [carboidratos $(\%)=17,99-0,62^{*}$ dose de $\mathrm{KCl}$ ] diminuíram estatisticamente $(\mathrm{p} \leq 0,05)$ com o aumento da dose de potássio fornecido. Azeredo, Lima e Cassino (2004) verificaram uma diminuição nos carboidratos solúveis na cv. Achat com o aumento da adubação potássica. Diferentemente, neste trabalho, as cvs. Atlantic e Innovator tenderam a aumentar os carboidratos com o incremento da dose de $\mathrm{K}_{2} \mathrm{SO}_{4}$, porém sem significância estatística $(\mathrm{p} \leq 0,05)$.

Os valores de carboidratos obtidos (Tabela 2) demonstram que a cultivar que apresentou os maiores teores médios de carboidratos foi a Innovator (17,72\%), estando de acordo com Maccari Júnior (1997), que diz que os carboidratos correspondem em média a $18,4 \%$ no tubérculo in natura, podendo variar de 8,0 a $29,4 \%$ e são um dos componentes da batata que mais influenciam a qualidade para consumo ou processamento.

A quantidade média de carboidratos (17,00\%) foi inferior ao verificado por Stertz, Rosa e Freitas (2005), que obtiveram $18,05 \%$ para os carboidratos totais (soma dos carboidratos, açúcares e fibras) e superior aos relatados na literatura (14,7\%) (TACO-UNICAMP, 2006).

Os carboidratos encontrados nos tubérculos cultivados com $\mathrm{K}_{2} \mathrm{SO}_{4}$ foram estatisticamente superiores ao cloreto $(\mathrm{p} \leq 0,05)$, o que sugere que a fonte sulfato tem melhor efeito na obtenção deste nutriente. De acordo com Bregagnoli (2006), o KCl gera um efeito prejudicial à planta, quando aplicado tardiamente, que devido à assimilação do íon cloro afeta as combinações com fósforo, diminuindo a síntese de carboidratos.

\subsection{Energia}

A energia teve comportamento muito semelhante aos carboidratos, indicando que os fatores cultivar, dose e fonte também interferem na quantidade calórica que os tubérculos propiciam. De acordo com Favoretto (2005), a batata é um dos alimentos mais completos, em que a energia é oriunda dos carboidratos.

A quantidade calórica tendeu a diminuir estatisticamente com o aumento da dose de adubação potássica para as cvs. Atlantic, Innovator e Shepody, adubadas com $\mathrm{KCl}$, conforme pode ser verificado pelas equações de regressão: [energia $\left(\mathrm{kcal} .100 \mathrm{~g}^{-1}\right)$ cv. Atlantic $=84,77-2,78^{*} \mathrm{X}$; energia $\left(\mathrm{kcal} .100 \mathrm{~g}^{-1}\right)$ $\mathrm{cv}$. Innovator $=86,92-2,77^{\star} \mathrm{X}$; energia $\left(\mathrm{kcal} .100 \mathrm{~g}^{-1}\right)$ cv. Shepody $=81,77-2,78^{\star} \mathrm{X}$; sendo $\mathrm{X}=$ dose de $\left.\mathrm{KCl}\right]$.

O valor energético médio variou de 70,84 a $80,40 \mathrm{kcal} 100 \mathrm{~g}^{-1}$ para as cvs. Asterix e Innovator, respectivamente, com um teor médio de 76,82 kcal.100 g ${ }^{-1}$ (Tabela 2), sendo superior ao registrado por Stertz, Rosa e Freitas (2005), que encontraram $61,00 \mathrm{kcal} .100 \mathrm{~g}^{-1}$ para os tubérculos da cv. Monalisa cultivados no sistema convencional e $64,00 \mathrm{kcal}^{1} 100 \mathrm{~g}^{-1}$ relatados pela TACOUNICAMP (2006). Os valores energéticos foram estatisticamente superiores $(\mathrm{p} \leq 0,05)$ para os tubérculos cultivados com $\mathrm{K}_{2} \mathrm{SO}_{4}$ e podem ser atribuídos aos maiores teores de proteínas, lipídios e carboidratos observados nesta fonte.

\subsection{Amido}

O teor de amido é um dos itens na composição química dos tubérculos que determina a qualidade interna da batata para fritura (MORENO, 2000).

A análise de variância para o amido (Tabela 1) demonstrou que os fatores cultivar, dose e fonte influenciaram o amido dos tubérculos. Comportamento semelhante aos observados com os carboidratos (item 3.6), pois, de acordo com Favoretto (2005), dentro dos carboidratos, o amido é o que está em maior quantidade nos tubérculos.

Com a análise de regressão simples, foi possível observar que o amido tende a diminuir com o aumento da dose. Esse comportamento é explicado por Imas e Bansal (1999), que relatam que apesar do potássio ativar enzimas envolvidas na formação de amido, pode reduzir seu teor com um aumento da umidade nos tubérculos. Efeito significativo na diminuição do amido foi observado para as cvs. Innovator $\left(\mathrm{y}=18,19-0,72^{\star} \mathrm{X}\right)$ e Shepody $\left(y=16,68-0,58^{\star} X\right)$ cultivadas com cloreto.

Bregagnoli (2006) e Westermann et al. (1994) observaram que o aumento da dose de potássio $\left(\mathrm{KCl}\right.$ ou $\left.\mathrm{K}_{2} \mathrm{SO}_{4}\right)$ propicia uma diminuição no amido devido à elevação da quantidade de água nos tubérculos. Imas e Bansal (1999) relatam que alta concentração de potássio nos tubérculos aumenta a absorção de água, isso devido aos efeitos osmóticos de concentrações aumentadas do mineral no tecido (STARK et al., 2007).

Observando-se o amido (Tabela 2), nota-se que as cvs. Innovator e Atlantic apresentaram os maiores valores médios, 16,45 e $16,42 \%$, respectivamente, mostrando não haver diferença estatística $(\mathrm{p} \leq 0,05)$ entre elas. A cv. Shepody apresentou $15,58 \%$ de amido, sendo diferente das demais cultivares e superior à cv. Asterix, que apresentou os menores valores (14,63\%), diferindo estatisticamente das demais cultivares. Para Rodrigues Robles (2003), as batatas apresentam em média $16 \%$ do peso in natura de amido, sendo este dependente da cultivar.

De acordo com Bregagnoli (2006), o amido difere entre as cultivares. No seu estudo de cultivo de batatas em diferentes adubações em solo de baixa fertilidade, observou que a cv. Atlantic apresentou amido superior a $17,5 \%$ e para a cv. Asterix valores maiores que $16,5 \%$.

Sharma e Arora (1988) não verificaram alterações no amido com a adubação potássica em diferentes doses; o teor variou de 14,9 a $15,2 \%$, inferior ao obtido no presente trabalho. Se o destino dos tubérculos for a indústria de fritas, o amido deve ser superior a 15\% (KITA, 2002), pois será responsável pela coloração da batata frita (VERGARA et al., 2006).

A fonte sulfato diferiu estatisticamente da de cloreto, fornecendo maiores quantidades de amido. Imas e Bansal (1999) relatam que normalmente o uso de adubos com $\mathrm{K}_{2} \mathrm{SO}_{4}$ propicia tubérculos com teores de amido superiores aos que utilizam $\mathrm{KCl}$.

\subsection{Potássio}

A análise de variância do potássio (Tabela 1) demonstrou que apenas as interações cultivar $\times$ dose e dose $\times$ fonte não demonstraram efeitos significativos. A cv. Asterix adubada com 
$\mathrm{K}_{2} \mathrm{SO}_{4}$ apresentou tendência em diminuir o potássio (potássio $\left(\mathrm{mg} .100 \mathrm{~g}^{-1}\right)=500,18-15,54^{\star}$ dose $\mathrm{K}_{2} \mathrm{SO}_{4}$ ) nos tubérculos com o aumento da dose $(\mathrm{p} \leq 0,01)$ e as cvs. Innovator [potássio $\left(\mathrm{mg} .100 \mathrm{~g} \mathrm{~g}^{-1}\right)=371,28+32,67^{\star}$ dose $\mathrm{K}_{2} \mathrm{SO}_{4}$ ] e Shepody [potássio $\left(\mathrm{mg} .100 \mathrm{~g} \mathrm{~g}^{-1}\right)=420,70+22,45^{\star}$ dose de $\left.\mathrm{KCl}\right]$ mostraram que o aumento da dose de adubação potássica tende a aumentar o teor deste mineral nos tubérculos $(\mathrm{p} \leq 0,01)$. De acordo com Pauletti e Menarin (2004), o excesso de potássio fornecido às batateiras faz com que ocorra o aumento de sua absorção e acúmulo na planta.

O teor de potássio está mostrado na Tabela 2 e apresentou variação de 352,50 a $549,91 \mathrm{mg} .100 \mathrm{~g}^{-1}$ nos tubérculos in natura, superior aos valores de Stertz, Rosa e Freitas (2005), que encontraram 147,90 $\mathrm{mg}$ de potássio em $100 \mathrm{~g}$ de amostra e aos $302 \mathrm{mg} .100 \mathrm{~g}^{-1}$ relatados pela TACO-UNICAMP (2006). A fonte cloreto apresentou as maiores quantidades de potássio, diferindo estatisticamente $(\mathrm{p} \leq 0,05)$ da fonte sulfato.

Os resultados encontrados estão de acordo com Cieslik e Sikora (1998), que observaram variação de 250 a $601 \mathrm{mg} .100 \mathrm{~g}^{-1}$ de amostra, porém as condições pelas quais os tubérculos foram produzidos e as cultivares eram diferentes deste estudo.

\section{Conclusões}

O trabalho reproduziu a prática dos bataticultores da região, os quais utilizam grandes quantidades de adubos para se obter uma batata de ótima qualidade para processamento e com isso alterando a composição química dos tubérculos para o consumo.

Com base nos resultados obtidos, pode-se concluir que a composição química das batatas é dependente da cultivar e da adubação potássica (dose e fonte) empregada. Em relação às cultivares Atlantic, Asterix, Innovator e Shepody, todas as variáveis dependentes analisadas são diferentes. A cv. Atlantic apresentou as maiores quantidades de potássio e cinzas; a cv. Asterix, as menores de vitamina $C$, proteínas, lipídios, carboidratos, energia e amido, e a maior umidade; a cv. Innovator mostrou os maiores teores de proteínas, lipídios, carboidratos, energia e amido e os menores de umidade, cinzas e potássio; e a cv. Shepody, a maior quantidade de vitamina $\mathrm{C}$.

A dose de potássio não afetou os níveis de lipídios, porém a vitamina $\mathrm{C}$, proteínas, carboidratos, amido e energia diminuíram com o aumento da quantidade de potássio fornecida. Para as cinzas e potássio, o efeito foi contrário, o aumento da dose fez com que eles se elevassem.

Em relação à fonte de adubação potássica utilizada, a de sulfato foi a melhor fonte, pois os teores obtidos com cloreto mostraram-se inferiores para as variáveis vitamina $\mathrm{C}$, cinzas, carboidratos, energia e amido.

\section{Referências bibliográficas}

ASSOCIATION OF OFFICIAL ANALYTICAL CHEMISTS - AOAC. Official methods of analysis. 17 ed. Gaythersburg, M.D., 2000.

AZEREDO, E. H.; LIMA, E.; CASSINO, P. C. R. Impacto dos nutrientes $\mathrm{N}$ e K e de açúcares solúveis sobre populações de Diabrotica speciosa (Germar) (Coleoptera, Chrysomelidae) e Agrotis ipsilon (Hüfnagel) (Lepidoptera, Noctuidae) na cultura da batata, Solanum tuberosum
L. (Solanaceae). Revista Brasileira de Entomologia, v. 48, n. 1, p. 105-113, 2004.

BELANGER, G. et al. Nitrogen fertilization and irrigation affects tuber characteristics of two potato cultivars. American Journal of Potato Research, v. 79, n. 4, p. 269-279, 2002.

BRASIL. Ministério da Agricultura, Pecuária e Abastecimento. Portaria $n^{\circ} 69$, de 21 de fevereiro de 1995. Aprova a norma de identidade, qualidade, acondicionamento e embalagem da batata para comercialização. Diário Oficial da República Federativa do Brasil, Brasília, fevereiro de 1995.

BRASIL. Ministério da Saúde. Agência Nacional de Vigilância Sanitária. Instituto Adolfo Lutz. Métodos Físicos e Químicos para Análise de Alimentos. 4. ed. Brasília, 2005. 1018 p.

BREGAGNOLI, M. Qualidade e produtividade de cultivares batata para indústria sob diferentes adubações. Piracicaba, 2006. 141 p. Tese (Doutorado em Agronomia, Área de Concentração Fitotecnia) - Escola Superior de Agricultura "Luiz de Queiroz", Universidade de São Paulo.

CIESLIK, E.; SIKORA, E. Correlation between the levels of nitrates and nitrites and the contents of potassium, calcium and magnesium in potato tubers. Food Chemistry, v. 63, n. 4, p. 525-528, 1998.

CONCEIÇÃO, A. M.; FORTES, G. R. L.; SILVA, J. B. Influência do ácido acetilsalicílico, da sacarose e da temperatura na conservação in vitro de segmentos caulinares de batata. Horticultura Brasileira, v. 17, n. 3, p.182-185, nov. 1999.

DARWISH, T. et al. Fertigation and Conventional PotassiumApplication to Field Grown Potato in Lebanon: Perspective to Enhance Efficiency. In: IPI REGIONAL WORKSHOP ON POTASSIUM AND FERTIGATION DEVELOPMENT IN WEST ASIA AND NORTH ÁFRICA, 2004. Anais eletrônicos... Disponível em: <http://www. ipipotash.org/udocs/Fertigation\%20and\%20Conventional\%20 Potassium.pdf> Acesso em: 18 de Janeiro de 2007.

EREIFEJ, K. I. et al. Chemical composition variations on tissues and processing characteristics in ten potato cultivars grown in Jordan. American Potato Journal, v. 74, n. 1, p. 23-30, 1997.

FAVORETTO, P. Parâmetros de crescimento e marcha de absorção de nutrientes na produção de minitubérculos de batata cv. Atlantic. Piracicaba, 2005. 98 p. Tese (Mestrado em Agronomia, Área de Concentração Fitotecnia) - Escola Superior de Agricultura "Luiz de Queiroz", Universidade de São Paulo.

IMAS, P.; BANSAL, S. K. Potassium and integrated nutrient management in potato. In: GLOBAL CONFERENCE ON POTATO, 6-11 dezembro, 1999, New Delh, Índia. Disponível em: <http://www.ipipotash.org/ presentn/kinmp.html> Acesso em: 28 de Novembro de 2003.

JORGE, N.; LUNARDI, V. M. Influência dos tipos de óleos e tempos de fritura na perda de umidade e absorção de óleo em batatas fritas. Ciência e Agrotecnologia, v. 29, n. 3, p. 635-641, 2005.

KITA, A. The influence of potato chemical composition on crisp texture. Food Chemistry, v. 76, n. 2, p. 173-179, 2002.

KOEHLER, H. S. Estatística Experimental. Curitiba: Universidade Federal do Paraná, 1999.

LEE, S. K.; KADER, A. A. Preharvest and postharvest factors influencing vitamin $\mathrm{C}$ content of horticultural crops. Postharvest Biology and Technology, v. 20, n. 3, p. 207-220, 2000.

LEONEL, M.; CEREDA, M. P. Caracterização físico-química de algumas tuberosas amiláceas. Ciência e Tecnologia de Alimentos, v. 22, n. 1, p. 65-69, 2002.

LOVE, S. L. et al. Variety selection and management. In: STARK, J. C.; LOVE, S. L. Potato Production Systems. Idaho: Idaho Center for Potato Research \& Education, 2003. 420 p. Disponível em: 
$<$ http://www.ag.uidaho.edu/potato/production/>. Acesso em: 08 de Janeiro de 2007.

MACCARI JÚNIOR, A. Uso da levedura amilolítica Schwanniomyces castellii para hidrólise do amido de batata e produção de etanol. Curitiba, 1997. 94 p. Dissertação (Mestrado em Tecnologia Química) Universidade Federal do Paraná.

MALLMANN, N. Efeito da adubação na produtividade, qualidade e sanidade de batata cultivada no centro-oeste paranaense. Curitiba, 2001. 129 p. Dissertação (Mestrado em Agronomia, Área de Concentração em Produção Vegetal) - Universidade Federal do Paraná.

MALLMANN, N.; LUCCHESI, L. A. C. Efeito da adubação na produtividade, qualidade e sanidade de batata cultivada no centrooeste Paranaense. Scientia Agraria, v. 3, n. 1-2, p. 113-132, 2002.

MORENO, J. D. Calidad de la papa para usos industriales. Corpoica: [s.n.], 2000. Disponível em: <http://www.redepapa.org/calidadpapa. pdf $>$. Acesso em: 10 de Outubro de 2003.

MICHIGAM STATES UNIVERSITY - MSU. MSTATC versão 2.10. East Lansing, MI, 1989. (2 disquetes $3 \frac{1}{2} 2$ pol., MSDOS).

NAKANO, D. H.; DELEO, J. P. B.; BOTEON, M. Choque de competitividade. Hortifruti Brasil, n. 51, p. 6-17, 2006.

PAULETTI, V.; MENARIN, E. Época de aplicação, fontes e doses de potássio na cultura da batata. Scientia Agraria, v. 5, n. 1-2, p. 15-20, 2004.

PINELI, L. L. O. et al. Caracterização química e física de batatas 'Ágata' minimamente processadas, embaladas sob diferentes atmosferas modificadas ativas. Pesquisa Agropecuária Brasileira, v. 40, n. 10, p. 1035-1041, 2005.

PINELI, L. L. O. et al. Caracterização química e física de batatas ágata e monalisa minimamente processadas. Ciência e Tecnologia de Alimentos, v. 26, n. 1, p. 127-134, 2006.

POPP, P. R. Batata para processamento - aptidão da matéria prima para processamento. Curitiba: [s.n.], 2005. Disponível em: <http://www. abbabatatabrasileira.com.br/minas2005/02\%20-\%20Aptid\%E3o\%20 da\%20mat\%E9ria\%20prima\%20para\%20a\%20ind\%FAstria\%2001. pdf>. Acesso em: 31 de Maio de 2006.

REIS JÚNIOR, R. A.; MONNERAT, P. H. Exportação de nutrientes nos tubérculos de batata em função de doses de sulfato de potássio. Horticultura Brasileira, v. 19, n. 3, p. 227-231, 2001.

RODRIGUES ROBLES, W. G. Dióxido de carbono via fertirrigação em batateira (Solanum tuberosum L.) sob condições de campo. Piracicaba, 2003. 160 p. Tese (Doutorado em Agronomia, Área de Concentração Irrigação e Drenagem) - Escola Superior de Agricultura "Luiz de Queiroz", Universidade de São Paulo.

RODRIGUEZ-SAONA, L. E.; WROLSTAD, R. E. Influence of potato composition on chip color quality. American Potato Journal, v. 74, n. 2, p. 87-107, 1997.
SALAZAR, M.; BUSCH, L. Standards and Strategies in the Michigan Potato Industry. East Lansing: Michigan Agricultural Experiment Station, 2001. 16 p. Research Report 576.

SHARMA, U. C.; ARORA, B. R. Effect of applied on the starch, proteins and sugar in potatoes. Food Chemistry, v. 30, n. 4, p. 313-317, 1988.

SILVA, M. R.; CERQUEIRA, F. M.; SILVA, P. R. M. Batatas fritas tipo palito e palha: absorção de gordura e aceitabilidade. Nutrire, v. 26, n. 1, p. 51-62, 2003.

STARK, J. C. et al. Tuber quality. In: STARK, J. C.; LOVE, S. L. (Eds.). Potato Production Systems. Idaho: Idaho Center for Potato Research \& Education, 2003. 420 p. Disponível em: <http://www.ag.uidaho. edu/potato/production/>. Acesso em: 08 de Janeiro de 2007.

STERTZ, S. C.; ROSA, M. I. S.; FREITAS, R. J. S. Qualidade nutricional e contaminantes da batata (Solanum tuberosum L., solanaceae) convencional e orgânica na Região Metropolitana de Curitiba Paraná. Boletim do Centro de Pesquisa de Processamento de Alimentos, v. 23, n. 2, p. 383-396, 2005.

UNIVERSIDADE ESTADUAL DE CAMPINAS - UNICAMP. Tabela Brasileira de Composição de Alimentos - TACO. 2 ed. Campinas, 2006. 113 p.

TAIZ, L.; ZEIGER, E. Fisiologia vegetal. 3 ed. Porto Alegre: Artmed, 2004. 719 p.

UNIVERSIDADE DE SÃO PAULO - USP. Departamento de Alimentos e Nutrição Experimental/BRASILFOODS, Faculdade de Ciências Farmacêuticas. Tabela Brasileira de Composição de AlimentosUSP. Versão 4.1. São Paulo, 1998. Disponível em: <http://www.fcf. usp.br/tabela> Acesso em: 10 Out. 2005.

TRINDADE, J. L. F. Caracterização de algumas variedades de batata do Município de Contenda-PR e indicações quanto ao uso doméstico e fins tecnológicos. Curitiba, 1994. 91 p. Dissertação (Mestrado em Tecnologia Química) - Universidade Federal do Paraná.

VERGARA, P. et al. Estudo do comportamento de óleo de soja e de arroz reutilizados em frituras sucessivas de batata. Boletim do Centro de Pesquisa de Processamento de Alimentos, v. 24, n. 1, p. 207-220, 2006.

WESTERMANN, D. T. et al. Nitrogen and potassium fertilization of potatos: sugars and starch. American Potato Journal, v. 71, n. 7, p. 433-453, 1994.

ZORZELLA, C. A.; VENDRUSCOLO, J. L.; TREPTOW, R. O. Qualidade sensorial de "chips" de diferentes genótipos de batatas (Solanum tuberosum L.), cultivos de primavera e outono no Rio Grande do Sul. Revista Brasileira de Agrociência, v. 9, n. 1, p. 57-63, 2003.

ZORZELLA, C. A. et al. Caracterização física, química e sensorial de genótipos de batata processados na forma chips. Brazilian Journal of Food Technology, v. 6, n. 1, p. 15-24, 2003. 